\title{
Desalination of brackish groundwater by direct contact membrane distillation
}

\author{
D. Y. Hou, J. Wang, D. Qu, Z. K. Luan, C. W. Zhao and X. J. Ren
}

\begin{abstract}
The direct contact membrane distillation (DCMD) applied for desalination of brackish groundwater with self-made polyvinylidene fluoride (PVDF) membranes was presented in the paper. The PVDF membrane exhibited high rejection of non-volatile inorganic salt solutes and a maximum permeate flux $24.5 \mathrm{~kg} \mathrm{~m}^{-2} \mathrm{~h}^{-1}$ was obtained with feed temperature at $70^{\circ} \mathrm{C}$. The DCMD experimental results indicated that the feed concentration had no significant influence on the permeate flux and the rejection of solute. When natural groundwater was used directly as the feed, the precipitation of $\mathrm{CaCO}_{3}$ would be formed and clog the hollow fibre inlets with gradual concentration of the feed, which resulted in a rapid decline of the module efficiency. The negative influence of scaling could be eliminated by acidification of the feed. Finally, a $250 \mathrm{~h}$ DCMD continuous desalination experiment of acidified groundwater with the concentration factor at constant 4.0 was carried out. The permeate flux kept stable and the permeate conductivity was

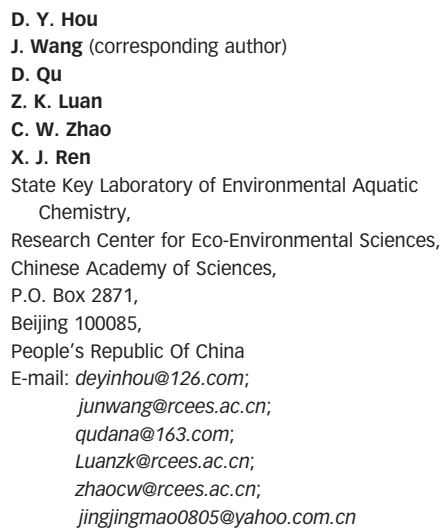
less than $7.0 \mu \mathrm{S} \mathrm{cm}^{-1}$ during this process. Furthermore, there was no deposit observed on the membrane surface. All of these demonstrated that DCMD could be efficiently used for production of high-quality potable water from brackish groundwater with water recovery as high as $75 \%$.

Key words | brackish groundwater, desalination, membrane distillation

\section{INTRODUCTION}

Water resources are becoming increasingly scarce in many areas of the world due to population growth, industrial development and severe drought. Compared with traditional water sources, development of unconventional water supplies, such as wastewater, brackish water, and seawater, is increasingly promoted worldwide ( $\mathrm{Xu}$ et al. 2008). China is a country with great variations in the spatial and temporal distribution of its water resources. There is more than sufficient water in the south but there is a water deficiency in the north (Zhou \& Tol 2004). In many parts of North and Northwest China, groundwater is brackish and it is difficult to supply sufficient high-quality potable water. To solve or eliminate water shortage problems, brackish groundwater desalination draws more and more attention as an alternative water supply source.

doi: $10.2166 /$ wst.2010.110
Nowadays, thermal evaporation (El-Dessouky et al. 2000; Hamed et al. 200I; Kamali \& Mohebinia 2008) and membrane technologies (Mohsen et al. 2003; Jaber \& Ahmed 2004) are the most commonly used methods for desalination. The evaporation method has been used for a long time because the operating principle and equipment are very simple and high purity fresh water can be obtained, which is widely used in the Middle East (Borsani \& Rebagliati 2005). However, its disadvantage is that the energy cost is very high. In the case of seawater desalination, the combined thermal and electrical energy consumed by a typical evaporation system with energy recovery is almost $30 \mathrm{~kJ} \mathrm{~L}^{-1}$ (Wade I993).

Reverse osmosis (RO) and nanofiltration (NF) are two common pressure driven membrane processes used for desalination. RO is actually efficient since it sharply reduced 
the content of inorganic matter present in water. But the RO membranes are particularly susceptible to scaling and fouling, so it is very difficult to maintain the constant permeate flux (Hasson et al. 200I). In addition, a high pressure is necessary in RO membrane system, which causes the treatment cost of desalination to increase (Afonso et al. 2004). In NF process, although less pressure is needed, NF can just ensure the reduction of bivalent ions and it is insufficient to obtain drinking water from brackish water which contains lots of monovalent ions: the total dissolved solid (TDS) of the permeate obtained with this process is superior to the standard value (Walha et al. 2007). Electrodialysis (ED) is an electrical-driven membrane technology, which is effective with salt removal from feed and not sensitive to $\mathrm{pH}$ or hardness levels. However, when using ED technology for desalination, treatment cost is directly related to the TDS concentration in feed. This technology is best used in treating brackish water with TDS up to $4,000 \mathrm{mg} \mathrm{L}^{-1}$ and not economical for higher TDS concentration (Younos \& Tulou 2005).

Membrane distillation (MD) is a thermally driven process that involves transport of water vapour through a porous hydrophobic membrane (Wang et al. 2008). During the MD process of solutions with non-volatile solutes, only water vapour can transfer through the membrane. It may be used as a substitute for conventional separation processes such as multistage vacuum evaporation, reverse osmosis, and distillation (Lawson \& Lloyd I997). Compared with these processes, the advantages of MD are as follows: (1) lower operating temperature and vapour space required than conventional distillation, (2) lower operating pressure than RO, (3) $100 \%$ (theoretical) rejection of non-volatile solute, (4) unlimited by high osmotic pressure and (5) lower energy consumption than multistage vacuum evaporation (El-Zanati \& El-Khatib 2007). Up to the present, MD has been applied for water desalination (M-Díez \& F-Díaz 200I), waste water reuse (Bader 2005), juice concentration processing (B-Bakó \& Koroknai 2006) and other industrial areas (Gryta \& Karakulski I999; Zakrzewska et al. 200I).

Direct contact membrane distillation (DCMD) is the best known configuration of $\mathrm{MD}$, in which the feed and the distillate are directly separated by the hydrophobic membrane. And DCMD is considered to be the most simple, economical and efficient configuration (Phattaranawik \& Jiraratananon 200I). The objective of this presented work was to investigate the feasibility of desalinating brackish groundwater by DCMD process. The effect of feed temperature, flow rate and feed salt concentration on the DCMD process performance was determined. Finally, the DCMD process with self-made PVDF membrane was applied to the desalination of natural brackish groundwater. The effect of pre-acidification on the DCMD process performance in terms of flux stability and rejection was also studied.

\section{MATERIALS AND METHODS}

\section{Feed solution}

The feed solution was the natural groundwater taken from the eastern region of Huanghua (Hebei Province, China). The quality of the untreated groundwater is shown in Table 1. The groundwater contained $2,340 \mathrm{mg} \mathrm{L}^{-1}$ of TDS and it was brackish.

The ion compositions of the groundwater were analysed using several methods. Analysis of $\mathrm{F}^{-}, \mathrm{Cl}^{-}$and $\mathrm{SO}_{4}^{2-}$ were made by ion chromatograph (861, Metrohm, Switzerland). $\mathrm{K}^{+}, \mathrm{Na}^{+}, \mathrm{Ca}^{2+}$ and $\mathrm{Mg}^{2+}$ were analysed on ICP-AES (1200, Agilent, USA). Alkalinity, carbonate and bicarbonate were measured using an alkalinity titration, TDS using evaporation and the conductivity of the feed using a conductivity meter (CO150, HACH, USA).

\section{Membrane and membrane module}

The hydrophobic polyvinylidene fluoride (PVDF) hollow fibre membranes used in the experiments were

Table 1 | Quality of the untreated groundwater

\begin{tabular}{llll} 
Parameters & Value & Parameters & Value \\
\hline $\mathrm{K}^{+}\left(\mathrm{mg} \mathrm{L}^{-1}\right)$ & 45 & $\mathrm{SO}_{4}^{2-}\left(\mathrm{mg} \mathrm{L}^{-1}\right)$ & 312 \\
$\mathrm{Ca}^{2+}\left(\mathrm{mg} \mathrm{L}^{-1}\right)$ & 128 & $\mathrm{HCO}_{3}^{-}\left(\mathrm{mg} \mathrm{L}^{-1}\right)$ & 108 \\
$\mathrm{Na}^{+}\left(\mathrm{mg} \mathrm{L}^{-1}\right)$ & 560 & $\mathrm{pH}$ & 7.52 \\
$\mathrm{Mg}^{2+}\left(\mathrm{mg} \mathrm{L}^{-1}\right)$ & 96 & Temperature $\left({ }^{\circ} \mathrm{C}\right)$ & 16.6 \\
$\mathrm{~F}^{-}\left(\mathrm{mg} \mathrm{L}^{-1}\right)$ & 1.8 & Turbidity $(\mathrm{NTU})$ & 3.2 \\
$\mathrm{Cl}^{-}\left(\mathrm{mg} \mathrm{L}^{-1}\right)$ & 1,086 & $\mathrm{TDS}\left(\mathrm{mg} \mathrm{L}^{-1}\right)$ & 2,340 \\
\hline
\end{tabular}


Table 2 | Measured data of membrane characteristics

\begin{tabular}{ll} 
Parameter & Value \\
\hline Mean pore diameter $(\mu \mathrm{m})$ & 0.25 \\
OD/ID* $(\mathrm{mm} / \mathrm{mm})$ & $1.20 / 0.90$ \\
Wall thickness $(\mathrm{mm})$ & 0.15 \\
Porosity $(\%)$ & 73.70 \\
$\mathrm{LEPw}^{\dagger}(\mathrm{kPa})$ & 150 \\
\hline
\end{tabular}

*Outer diameter/inner diameter.

${ }^{\dagger}$ Liquid entry pressure of water.

self-prepared by dry/wet phase inversion process and the membrane characteristics are shown in Table 2.

The dry PVDF hollow fibres were assembled into a polyester tube (diameter $\left.(\mathrm{mm}) d_{\text {in }} / d_{\text {out }}=15 / 20\right)$ with two UPVC T-tubes and two ends of the bundle of fibres were sealed with solidified epoxy resin to form a membrane module. The module had a total length of $240 \mathrm{~mm}$ and an effective length of $100 \mathrm{~mm}$. The packing fraction of hollow fibres in the module was around 32\%. The total effective area of the module was about $150 \mathrm{~cm}^{2}$ based on the inner surface.

\section{Experimental setup}

The schematic representation of DCMD setup is shown in Figure 1. The hot feed flowed through the lumen side of the fibres and the cold distillate flowed through the shell side using two rotameters (LZS-15, Yuyao Yinhuan Flowmeter, China) to adjust the flow rate. Both solutions were circulated in the membrane module with the help of two magnetic pumps (MP-15RN, Shanghai Seisun Bumps, China).
The feed and the cold distillate flowed co-currently through the module and their temperature was controlled by water baths. The temperature of both fluids was monitored at the inlet and outlet of the membrane module using four Pt-100 thermoresistances connected to a digital meter (Digit RTD, model XMT-808, Yuyao Changjiang Temperature Meter Instruments, China) with an accuracy of $\pm 0.1^{\circ} \mathrm{C}$. The conductivity of the cold distillate was investigated with an electric conductivity monitor (CM-230A, Shijiazhuang Create Instrumentation Technologies, China).

\section{Solute rejection and permeability tests}

To investigate whether the self-prepared hydrophobic PVDF hollow fibre membranes were applicable for desalination, the DCMD of $0.1 \mathrm{M} \mathrm{NaCl}, \mathrm{MgSO}_{4}$ and $\mathrm{CaCl}_{2}$ aqueous solutions were conducted at $\mathrm{pH} 4.0$ and 9.0 with the feed solution at $50^{\circ} \mathrm{C}$ and the cold distillate water at $20^{\circ} \mathrm{C}$. The $\mathrm{pH}$ of the feed was adjusted by addition of $0.1 \mathrm{M}$ $\mathrm{HCl}$ or $0.1 \mathrm{M} \mathrm{NaOH}$. The feed and distillate flow rates were kept at 0.52 and $0.15 \mathrm{~m} \mathrm{~s}^{-1}$, respectively. The solute rejection coefficient $R$ of the membrane was calculated according to the following equation:

$R=\frac{C_{\mathrm{f}}-C_{\mathrm{p}}}{C_{\mathrm{f}}}$

where $C_{\mathrm{f}}$ is the concentration of the feed and $C_{\mathrm{p}}$ is the concentration of the permeate.

A set of DCMD experiments were carried out using deionised water as feed to test the water vapour permeability of the membrane. The mean feed temperature

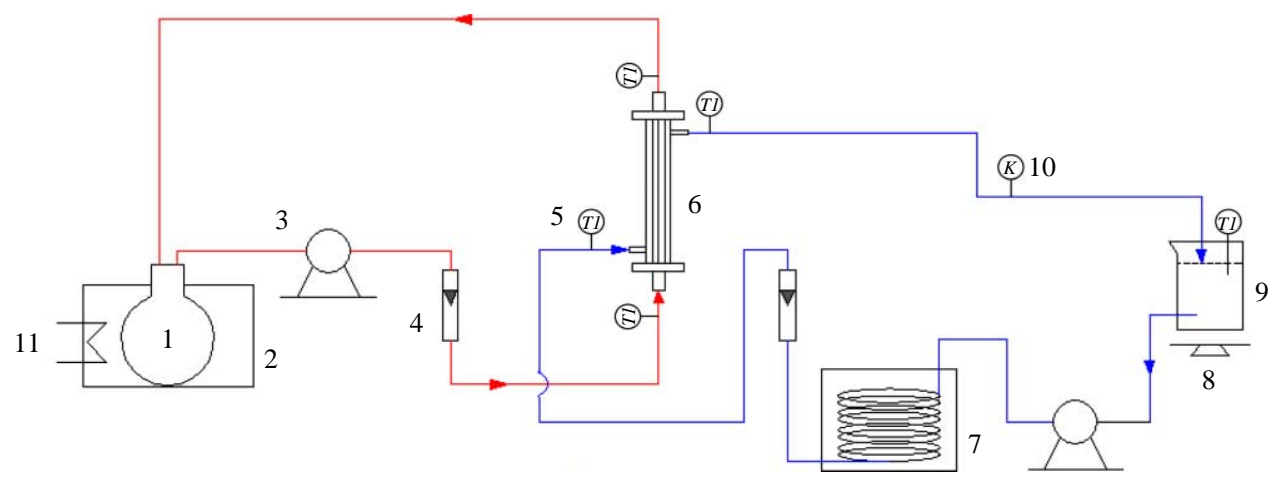

Figure 1 | Schematic diagram of the experimental DCMD setup. 1. Feed reservoir, 2. Water bath, 3. Circulating pump, 4. Flow meter, 5. Thermometer, 6. Membrane module, 7. Cooling coil, 8. Balance, 9. Permeate reservoir, 10. Conductivity meter, 11. Heater. 
varied from 40 to $70^{\circ} \mathrm{C}$ while the permeate temperature was kept at constant $20^{\circ} \mathrm{C}$. In addition, at each feed temperature, the influence of feed flow rate on permeate flux was also investigated with the feed flow rate $\left(V_{\mathrm{f}}\right)$ in the range of 0.17 to $0.52 \mathrm{~m} \mathrm{~s}^{-1}$ and the permeate flow rate $\left(V_{\mathrm{p}}\right)$ at $0.15 \mathrm{~m} \mathrm{~s}^{-1}$. The permeate flux of the membrane $J$ was calculated by the following equation:

$J=\frac{\Delta W}{A \Delta t}$

where $J$ is the permeate flux $\left(\mathrm{kg} \mathrm{m}^{-2} \mathrm{~h}^{-1}\right), \Delta W$ is the quantity of distillate $(\mathrm{kg}), A$ is the effective permeate area of the module $\left(\mathrm{m}^{2}\right)$ and $\Delta t$ is the sampling time $(\mathrm{h})$.

\section{Desalination experiment}

Desalination experiments of natural brackish groundwater without or with $0.1 \mathrm{M} \mathrm{HCl}$ addition were carried out. During the desalination process, the initial volume of feed was $5.0 \mathrm{~L}$ and there was no make-up water added into the feed reservoir, which meant that the feed solution was gradually concentrated. This concentration process was not stopped until the concentration factor reached 4.0 to get high water recovery.

To investigate the performance stability of DCMD, a $250 \mathrm{~h}$ continuous desalination experiment of acidified groundwater ( $\mathrm{pH}=4.0$ ) was carried out with the concentration factor at 4.0. In this case, the feed with initial volume of $5.0 \mathrm{~L}$ was at first concentrated to $1.25 \mathrm{~L}$, then the obtained permeate began to reflow to the feed reservoir to keep the concentration factor constant at 4.0 over the entire test course.

For all the desalination processes, the inlet temperatures of feed and cold distillate kept constant at $50^{\circ} \mathrm{C}$ and $20^{\circ} \mathrm{C}$, respectively. The feed flow rate was $0.52 \mathrm{~m} \mathrm{~s}^{-1}$, while the permeate side was $0.15 \mathrm{~m} \mathrm{~s}^{-1}$.

\section{SEM analysis}

Both the fresh and the used membrane samples were dried in air at room temperature. Then the membrane samples were sputter coated with gold and examined with a Hithche S-3000 scanning electron microscope (SEM) (Hitachi Ltd., Japan) to obtain high magnification membrane images.
Elemental analysis of the scaled membranes was accomplished using energy dispersive X-ray analysis (EDS) system.

\section{RESULTS AND DISCUSSION}

\section{Solute rejection tests}

The solute rejection test results are listed in Table 3. During the desalination processes of the prepared $\mathrm{NaCl}, \mathrm{MgSO}_{4}$ and $\mathrm{CaCl}_{2}$ aqueous solutions, all the solute rejection efficiencies could reach to 99.99\% at $\mathrm{pH} 4.0$ and 9.0, which indicated that the membrane had no selective rejection of different salts and the higher rejection can be obtained through the DCMD process whether the feed is alkali or acid. All of the test results showed that the self-prepared PVDF membrane was suitable for DCMD applications in brackish water desalination.

\section{Effect of feed temperature and flow rate}

The permeate flux as a function of feed temperature is shown in Figure 2. The experimental results showed that the feed temperature had a significant influence on the permeate flux. For example, the permeate flux increased from 6.0 to $24.5 \mathrm{~kg} \mathrm{~m}^{-2} \mathrm{~h}^{-1}$ when the feed temperature changed from 40 to $70^{\circ} \mathrm{C}$ with the feed flow rate at $0.52 \mathrm{~m} \mathrm{~s}^{-1}$. For all feed flow rates, the permeate flux increased with the feed temperature enhancement. This trend may be explained by the Antoine Equation (Yun et al. 2006) which predicts an exponential relationship between the driving force (vapour pressure difference) and temperature. Besides, the viscosity of the feed declined with the temperature increasing, which was favourable to enhance mass transfer coefficient.

Table 3 | Rejection of non-volatile solutes by DCMD

\begin{tabular}{lllll}
$\mathbf{p H}$ & $\begin{array}{l}\text { Solute } \\
(\mathbf{0 . 1} \mathbf{~ M )}\end{array}$ & $\begin{array}{l}\text { Feed conductivity } \\
\left(\mathbf{m s ~ c m}^{-\mathbf{1}}\right)\end{array}$ & $\begin{array}{l}\text { Permeate conductivity } \\
\left(\boldsymbol{\mu} \mathbf{S ~ c m}^{-\mathbf{1}}\right)\end{array}$ & $\begin{array}{l}\text { Rejection } \\
(\%)\end{array}$ \\
\hline 4.0 & $\mathrm{NaCl}$ & 10.27 & 2 & 99.99 \\
& $\mathrm{MgSO}_{4}$ & 5.62 & 3 & 99.99 \\
& $\mathrm{CaCl}_{2}$ & 14.64 & 2 & 99.99 \\
9.0 & $\mathrm{NaCl}^{*}$ & 10.45 & 2 & 99.99 \\
& $\mathrm{MgSO}_{4}$ & 5.55 & 2 & 99.99 \\
& $\mathrm{CaCl}_{2}$ & 14.42 & 3 & 99.99 \\
\hline
\end{tabular}




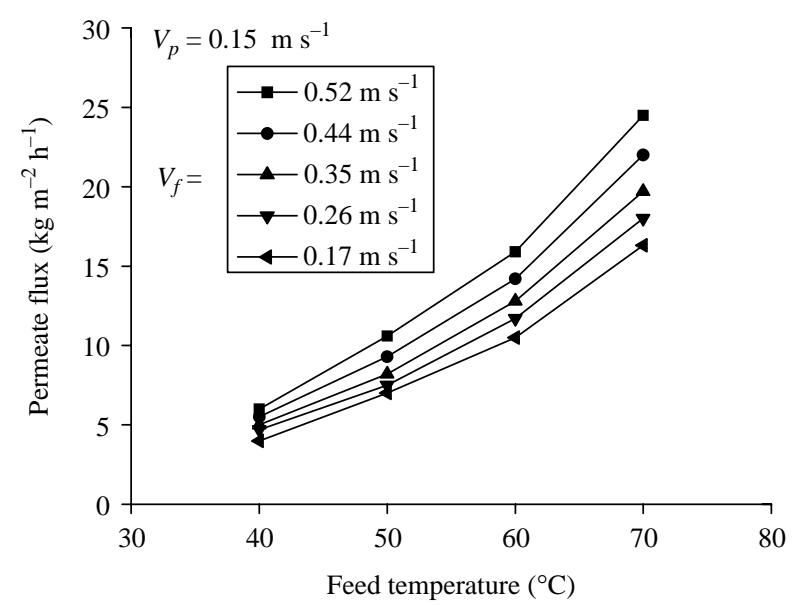

Figure 2 | Variation of permeate flux as a function of the feed temperature and flow rate.

It was also able to improve the permeate flux by increasing the feed flow rate, although the effect of the feed flow rate on the membrane permeability was not as significant as that of the feed temperature. This was because of the temperature and concentration polarisation phenomenon. The higher flow rate could diminish the polarisation effect, so the permeate flux increased with increasing the feed flow rate.

\section{Effect of feed concentration}

The effect of feed concentration on the permeate flux is presented in Figure 3. It can be found that the influence of feed $\mathrm{NaCl}$ concentration on the permeate flux was not as significant as that of feed temperature or feed flow rate and

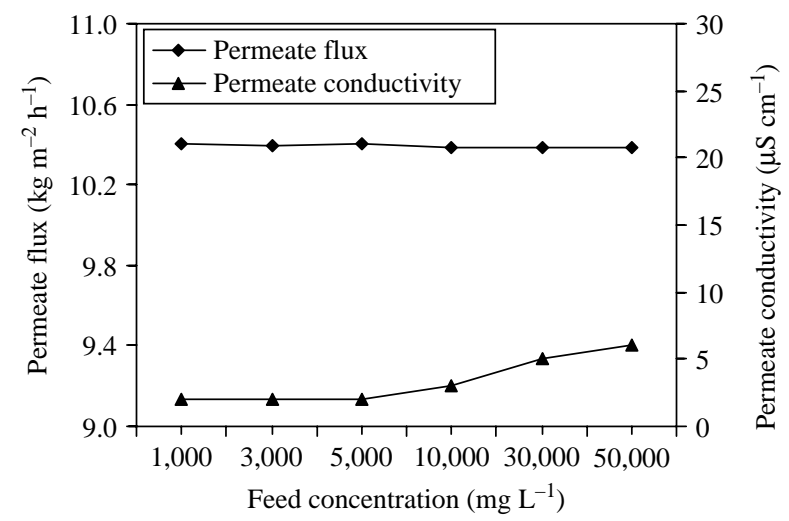

Figure 3 | Variation of permeate flux and permeate conductivity with different feed concentration. the permeate flux was hardly affected by the feed concentration in our studied range. This finding is in agreement with the result previously reported by Alklaibi \& Lior (2006). Based on a two-dimensional conjugate model, they drew a conclusion that the total mass transfer resistance kept constant with the increase of feed concentration in the DCMD process. According to Raoult's law, the saturated vapour partial pressure difference $(\Delta P)$ between pure water and dilute salt solution at same temperature can be calculated as follows:

$\Delta P=P_{0} \frac{m}{55.5}$

where $P_{0}$ is the saturated vapour pressure of pure water (Pa), $m$ is the molar concentration of solute in dilute salt solution (mol L $\left.{ }^{-1}\right)$. From Equation (3), it can be seen that the feed $\mathrm{NaCl}$ concentration has no significant effect on the saturated vapour partial pressure in the given $\mathrm{NaCl}$ concentration range of 1,000 to $50,000 \mathrm{mg} \mathrm{L}^{-1}$. The feed concentration had no significant influence on the total mass transfer resistance and the driving force of DCMD, so the permeate flux had no remarkable decline with the concentration increase.

In the $\mathrm{NaCl}$ concentration range of 1,000 to $5,000 \mathrm{mg} \mathrm{L}^{-1}$, feed concentration had no impact on the rejection, the permeate conductivity kept stable at $2 \mu \mathrm{S} \mathrm{cm}^{-1}$. When feed concentration increased to 50,000 $\mathrm{mg} \mathrm{L}^{-1}$, the permeate conductivity increased to $6 \mu \mathrm{S} \mathrm{cm}^{-1}$; this can be attributed to partial wetting phenomenon because a small amount of large pores existed on the membrane surface.

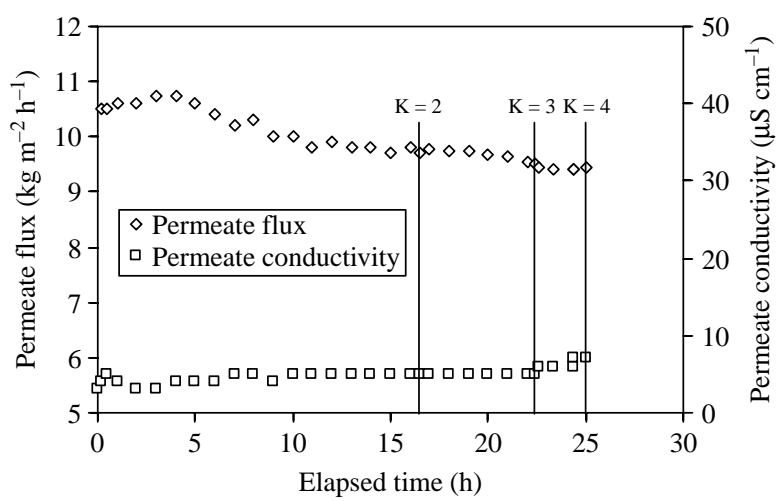

Figure 4 | Variation of permeate flux and permeate conductivity as a function of operating time of the DCMD process. 

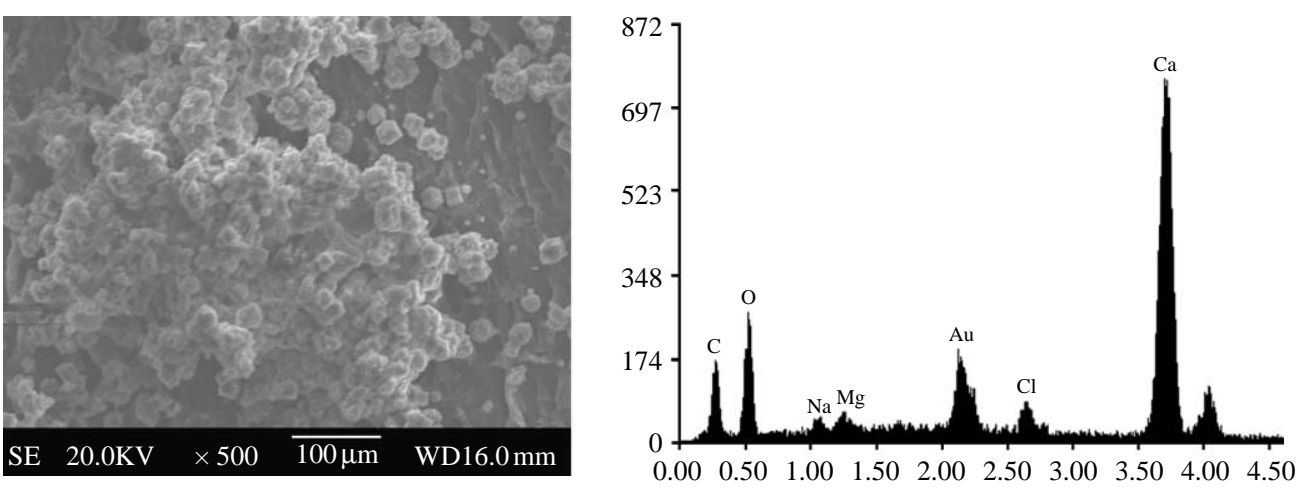

Figure 5 SEM image and microanalysis report of the deposit formed at the hollow fibre inlets during the DCMD process.

\section{DCMD process of brackish groundwater}

The results of gradual concentration of natural groundwater are shown in Figure 4. As can be seen, the permeate flux decreases sharply during a prolonged operation of the DCMD process. When the concentration factor $(K)$ reached 4.0, the permeate flux declined to $9.3 \mathrm{~kg} \mathrm{~m}^{-2} \mathrm{~h}^{-1}$ from initial permeate flux of $10.5 \mathrm{~kg} \mathrm{~m}^{-2} \mathrm{~h}^{-1}$.

All of these results were mainly due to the formation of deposit in the process of concentration of brackish groundwater. Heating the feeding water caused a shift from bicarbonate ion to the carbonate ion and scale deposits were formed from those salts whose solubility was generally limited because their concentrations increase with the gradual concentration of the feed. The accumulation of scale deposits at the hollow fibre inlets caused the clogging of partial hollow fibres and the decline of the feed flow rate. Furthermore, these scale deposits scattered on the membrane surface would pollute the membrane and cause

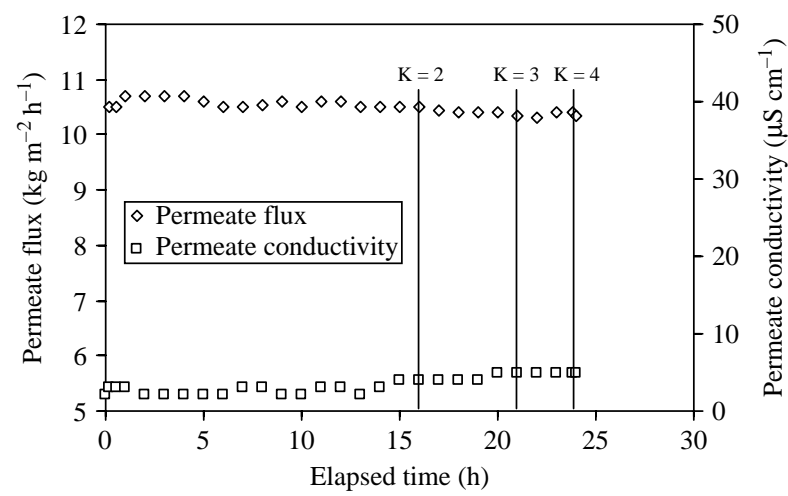

Figure 6 | Variation of permeate flux and permeate conductivity as a function of operating time of the DCMD process $(\mathrm{pH}=4.0)$. pore clogging. For these reasons, the permeate flux was decreased with the prolongation of operating time. Although the scale deposits polluted the membrane and a fraction of the membrane pores were wetted, the quality of obtained distillation was maintained. The SEM image of the deposits formed at the hollow fibre inlets is shown in Figure 5. The SEM-EDS analysis revealed that this deposit was mainly composed of $\mathrm{CaCO}_{3}$, with smaller amounts of the following elements: $\mathrm{Na}, \mathrm{Mg}$ and $\mathrm{Cl}$.

\section{DCMD of brackish groundwater with pre-acidification}

In order to achieve the decomposition of the bicarbonate ions in the groundwater and eliminate the negative influence of scale deposits on the DCMD performance, further studies of the DCMD process were carried out at the feed $\mathrm{pH} 4.0$ adjusted by addition of $0.1 \mathrm{~mol} \mathrm{~L}^{-1} \mathrm{HCl}$ to the water sample.

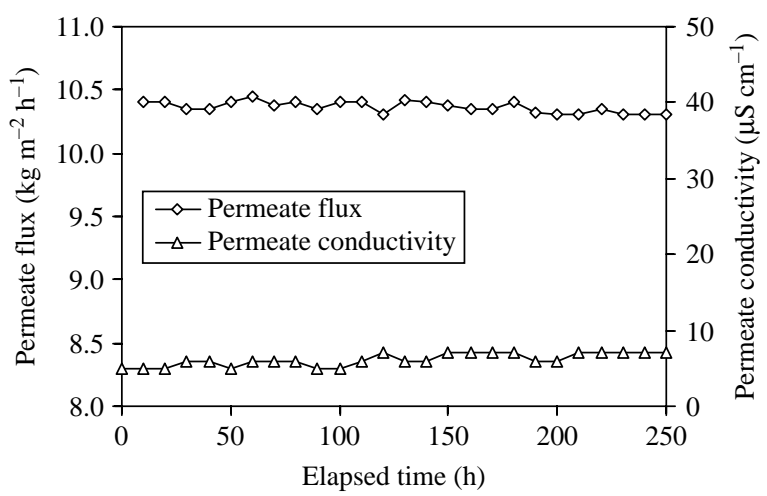

Figure $\mathbf{7} \mid$ Variation of permeate flux and permeate conductivity during $250 \mathrm{~h}$ desalination experiment. 


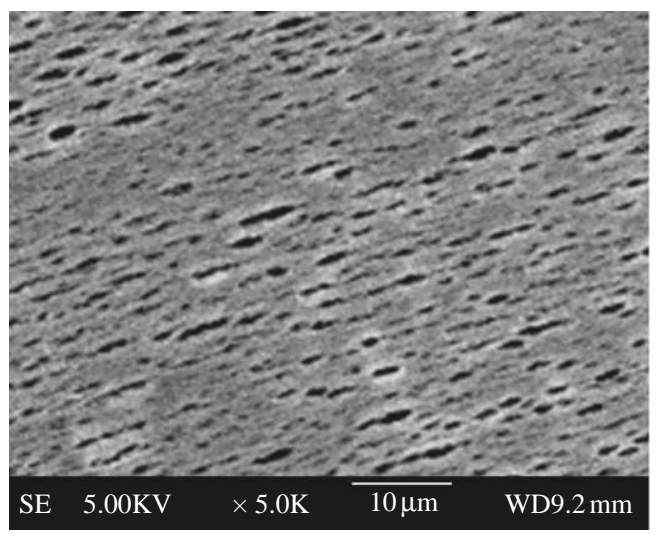

Inner surface

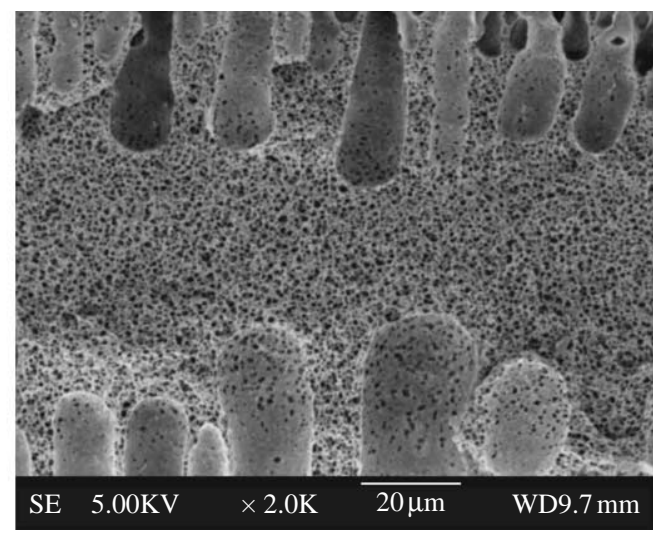

Middle structure

Figure 8 SEM micrographs of the PVDF membranes after $250 \mathrm{~h}$ desalination experiment.

The results of gradual concentration of pre-acidified groundwater are presented in Figure 6. As can be seen, the acidification of the feed enhances the stability of the process to a significant degree. There was no obvious decline of permeate flux during the whole concentration process and the permeate conductivity kept below $7.0 \mu \mathrm{S} \mathrm{cm}^{-1}$. All of these indicated that during this stage there was no scale deposit formed and the quality of the hydrophobic membrane was maintained well.

\section{Performance stability of DCMD}

To get high-quality drinking water, it is important to maintain the permeability and solute rejection during the practical application. To investigate the retaining performance stability of DCMD process, a $250 \mathrm{~h}$ continuous desalination experiment of acidified groundwater sample with the $\mathrm{pH}$ at constant 4.0 was carried out. During this process, the concentration factor was kept at 4.0, which meant that the water recovery reached $75 \%$. The other operating parameters of the DCMD process were in accordance with the solute rejection tests.

The results of desalination process are shown in Figure 7. It can be seen that the permeate flux maintains about $11.30-11.50 \mathrm{~kg} \mathrm{~m}^{-2} \mathrm{~h}^{-1}$ during experiment and there are no obvious changes of permeate flux. The permeate conductivity stabilised at about $5.0-7.0 \mu \mathrm{S} \mathrm{cm}^{-1}$. The SEM images of the hydrophobic PVDF membrane used in this process are presented in Figure 8. It can be found that there are no deposits formed on the inner surface of the membrane and there are also no marked changes of the membrane morphology observed. All of these demonstrated that the hydrophobic membrane had a stable permeability and solute rejection and the DCMD process was suitable for desalination of brackish groundwater.

\section{$\overline{\text { CONCLUSIONS }}$}

In the present work, the application of DCMD for desalination of natural brackish groundwater was investigated systematically.

The self-made PVDF membrane had high rejection of salt solutes, which was independent of the solution $\mathrm{pH}$. It was found that the permeate flux was enhanced with the increase of feed temperature or flow rate. In addition, the feed concentration had no significant impact on the permeate flux and the rejection of solute in the given feed salt concentration range.

In DCMD desalination process of natural brackish groundwater, it was necessary to acidify the feed. Heating of the feed would cause decomposition of bicarbonate ions and form $\mathrm{CaCO}_{3}$ deposit with the gradual concentration of the feed. The deposit resulted in a rapid decline of the module efficiency. The negative influence of scaling could be eliminated by acidification of the feed.

The results of a $250 \mathrm{~h}$ continuous desalination experiment of acidified brackish groundwater sample showed that the permeate flux and the quality of the distillate 
obtained kept stable. All of the results demonstrated that DCMD could be efficiently used for desalination of brackish groundwater with water recovery as high as $75 \%$.

\section{ACKNOWLEDGEMENTS}

This work was supported by the special fund from the National Natural Science Foundation of China (Grant No. 20907066) and the National High Technology Research and Development Program of China ("863" Program) (Grant No. 2008AA06A409-3, 2009AA063901).

\section{REFERENCES}

Afonso, M. D., Jaber, J. O. \& Mohsen, M. S. 2004 Brackish groundwater treatment by reverse osmosis in Jordan. Desalination 164(2), 157-171.

Alklaibi, A. M. \& Lior, N. 2006 Heat and mass transfer resistance analysis of membrane distillation. J. Membr. Sci. 282, 362-369.

Bader, M. S. H. A. 2005 A hybrid liquid-phase precipitation (LPP) process in conjunction with membrane distillation (MD) for the treatment of the INEEL sodium-bearing liquid waste. J. Hazard. Mater. 121, 89-108.

B-Bakó, K. \& Koroknai, B. 2006 Enhanced water flux in fruit juice concentration: coupled operation of osmotic evaporation and membrane distillation. J. Membr. Sci. 269, $187-193$.

Borsani, R. \& Rebagliati, S. 2005 Fundamentals and costing of MSF desalination plants and comparison with other technologies. Desalination 182, 29-37.

El-Dessouky, H. T., Ettouney, H. M. \& Al-Juwayhel, F. 2000 Multiple effect evaporation-vapour compression desalination processes. Chem. Eng. Res. Des. 78(4), 662-676.

El-Zanati, E. \& El-Khatib, K. M. 2007 Integrated membrane-based desalination system. Desalination 205, 15-25.

Gryta, M. \& Karakulski, K. 1999 The application of membrane distillation for the concentration of oil-water emulsions. Desalination 121, 23-29.

Hamed, O. A., Al-Sofi, M. Ak., Imam, M., Mustafa, G. M., Bamardouf, K. \& Al-Washmi, H. 20or Simulation of multistage flash desalination process. Desalination 134(1-3), 195-203.
Hasson, D., Drak, A. \& Semiat, R. 200I Inception of $\mathrm{CaSO}_{4}$ scaling on RO membranes at various water recovery levels. Desalination 139(1-3), 73-81.

Jaber, I. S. \& Ahmed, M. R. 2004 Technical and economic evaluation of brackish groundwater desalination by reverse osmosis (RO) process. Desalination 165, 209-213.

Kamali, R. K. \& Mohebinia, S. 2008 Experience of design and optimization of multi-effects desalination systems in Iran. Desalination 222, 639-645.

Lawson, K. W. \& Lloyd, D. R. 1997 Membrane distillation. J. Membr. Sci. 124, 1-25.

M-Díez, L. \& F-Díaz, F. J. 20or Desalination of brines by membrane distillation. Desalination 137, 267-273.

Mohsen, M. S., Jaber, J. O. \& Afonso, M. D. 2003 Desalination of brackish water by nanofiltration and reverse osmosis. Desalination 157(1-3), 167.

Phattaranawik, J. \& Jiraratananon, R. 200I Direct contact membrane distillation: effect of mass transfer on heat transfer. J. Membr. Sci. 188, 137-143.

Wade, N. M. 1993 Technical and economic evaluation of distillation and reverse osmosis desalination processes. Desalination 93, 343-363.

Walha, K., Amar, R. B., Firdaous, L., Quéménéur, F. \& Jaouen, P. 2007 Brackish groundwater treatment by nanofiltration, reverse osmosis and electrodialysis in Tunisia: performance and cost comparison. Desalination 207(1-3), 95-106.

Wang, K. Y., Chung, T.-S. \& Gryta, M. 2008 Hydrophobic PVDF hollow fiber membranes with narrow pore size distribution and ultra-thin skin for the fresh water production through membrane distillation. Chem. Eng. Sci. 63(9), 2587-2594.

Xu, P., Drewes, J. E., Heil, D. \& Wang, G. 2008 Treatment of brackish produced water using carbon aerogel-based capacitive deionization technology. Water Res. 42(10-11), $2605-2617$

Younos, T. \& Tulou, K. E. 2005 Overview of desalination techniques. J. Contemp. Water Res. Educ. 132, 3-10.

Yun, Y., Ma, R., Zhang, W., Fane, A. G. \& Li, J. 2006 Direct contact membrane distillation mechanism for high concentration $\mathrm{NaCl}$ solutions. Desalination 188, 251-262.

Zakrzewska, T. G., Harasimowicz, M. \& Chmielewski, A. G. 200I Membrane processes in nuclear technology-application for liquid radioactive waste treatment. Sep. Purif. Technol. 22, $617-625$.

Zhou, Y. \& Tol, R. S. J. 2004 Implications of desalination for water resources in China-an economic perspective. Desalination 164, 225-240. 